\title{
Technological Adaptation of Internal Dumping to the Operating Mode of Open Pit when Developing Inclined and Steeply Dipping Coal Seams Strata
}

\author{
Alexei Selyukov* \\ T.F. Gorbachev Kuzbass State Technical University, Department of Open-pit Mining, 650000 \\ Kemerovo, 28 Vesennyaya st., Russian Federation
}

\begin{abstract}
With surface mining of inclined and steeply dipping coal deposits, the so-called deeping longitudinal mining methods with a gradual deepening of mining from the surface to the final depth are widely spread, while orienting the mining front along the strike line of the seams (strata). When using such mining methods, the volumes of internal dumping are limited or completely absent; there is a peak-like increase in overburden volumes and transportation distance, the land resources disturbing proceeds at a progressive pace. In this regard, it is obvious that an important production task is to find technological solutions and methods to develop coal deposits that reduce the environmental hazard and increase resource conservation in mining by placing overburden in the mined-out space while reducing the area for external dumps and disturbing the earth's surface. If this is not foreseen at the present time, then all coal surface mines in the coming decades will be limited by their own external dumps of overburden, and their further development will be problematic.
\end{abstract}

\section{Introduction}

It is known from a number of scientific publications [1-5] that the following types of transverse technologies can be used in the development of inclined and steeply dipping coal deposits: deeping-continuous, step-by-step deepening, block-layer, shuttle-layer. These technologies are characterized by two stages in the development of mining operations:

1. The formation of the initial storage capacity within the boundaries of the quarry field for internal dumps.

2. Development of the main part of quarry field with overburden storage in the worked out area of the open pit.

However, as a comprehensive analysis of the design material shows, the introduction of resource-saving technologies into design practice does not take place from the standpoint of their integrated implementation, but only fragmentarily. In addition, the introduction of transverse mining technologies into design practice should be accompanied by an additional justification of their parameters and areas of effective application, in relation to specific

* Corresponding author: sav.ormpi@kuzstu.ru 
mining, geological and technological conditions. It means that additional structural and parametric studies must be carried out in relation to the conditions of the operating surface mines.

This circumstance is explained by the following fact. The general theoretical basis for the formation of technologies with internal dumping was the works of Russian mining scientists, starting from the 1960 s, and the intensity of development in conjunction with the constantly changing conditions of surface mining has increased many times over. As one of the solutions to this technological problem, the transformation from longitudinal deepening into transverse mining method for the operating mode of surface mines of Kemerovo region-Kuzbass (Western Siberia, Russia, largest national coal basin, 230 million tons mined in 2019 [6-7]) can be proposed.

\section{Methods}

To study the "physical nature" of the process of switching one type of mining methods into another [8], the process of technological transformation of the working area of a quarry field is distributed in detail over the following hierarchical levels (Fig. 1-4):

I - main types of transverse mining methods;

II - stages of mining operations development with transverse mining method (preparation of a container for an internal dump, taking into account the worked-out space, development of the main part of the field with predominant internal dumping);

III - directions of development of the front of stripping and mining operations (in the profile and plan of the quarry field);

IV - construction of the face and dump sides of the quarry field (in the coal-rich and coalfree zones).

In addition, during technological transformation, the quarry field is additionally divided into stages: A - longitudinal deepening mining method (mined-out space); B - contours of the container for the internal dump; A1 - the zone of the remaining part of the quarry field, where mining operations can be carried out during the construction of the storage for the dump; $\mathrm{C}$ - the main (remaining after the construction of the storage for the internal dump) part of the open pit mine.

Taking into account the practice of the coal surface mines of the Kemerovo regionKuzbass and the forms of occurrence of the strata of inclined and steep coal seams, naturaland-technological forms and options for the placement of workings for the internal dump in the stratigraphic zones of the quarry field were identified:

- trapezoidal form with one or two-sided working area,

triangular form with one-sided working area,

- linear-oblique-angled form,

- curvilinear closed or open form, sequentially doubled, tripled, etc.

These aforementioned forms of quarry fields together form the spatial form of the original mine workings. 


I. Main types of transverse mining m ethods

Fig. 1. Interpretation of the technological process of transformation of longitudinal deepening into transverse mining method for the operating surface mine (for advancing and steep deepening mining methods - Stages I-III).

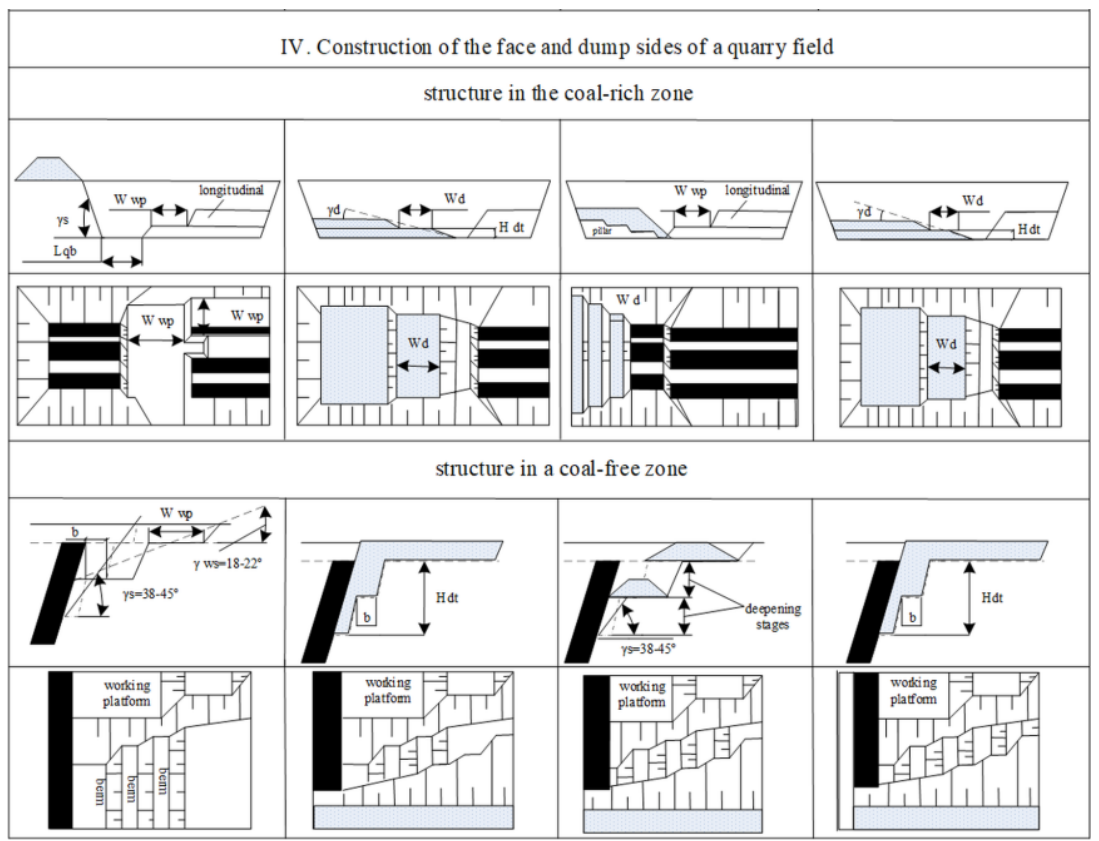

Fig. 2. Interpretation of the technological process of transformation of longitudinal deepening into transverse mining method for the operating surface mine (for advancing and steep deepening mining methods - Stage IV). 


I. Main types of transverse mining method

Fig. 3. Interpretation of the technological process of transformation of longitudinal deepening into transverse mining method for the operating surface mine (for shuttle and block-layer mining methods - Stages I-III).

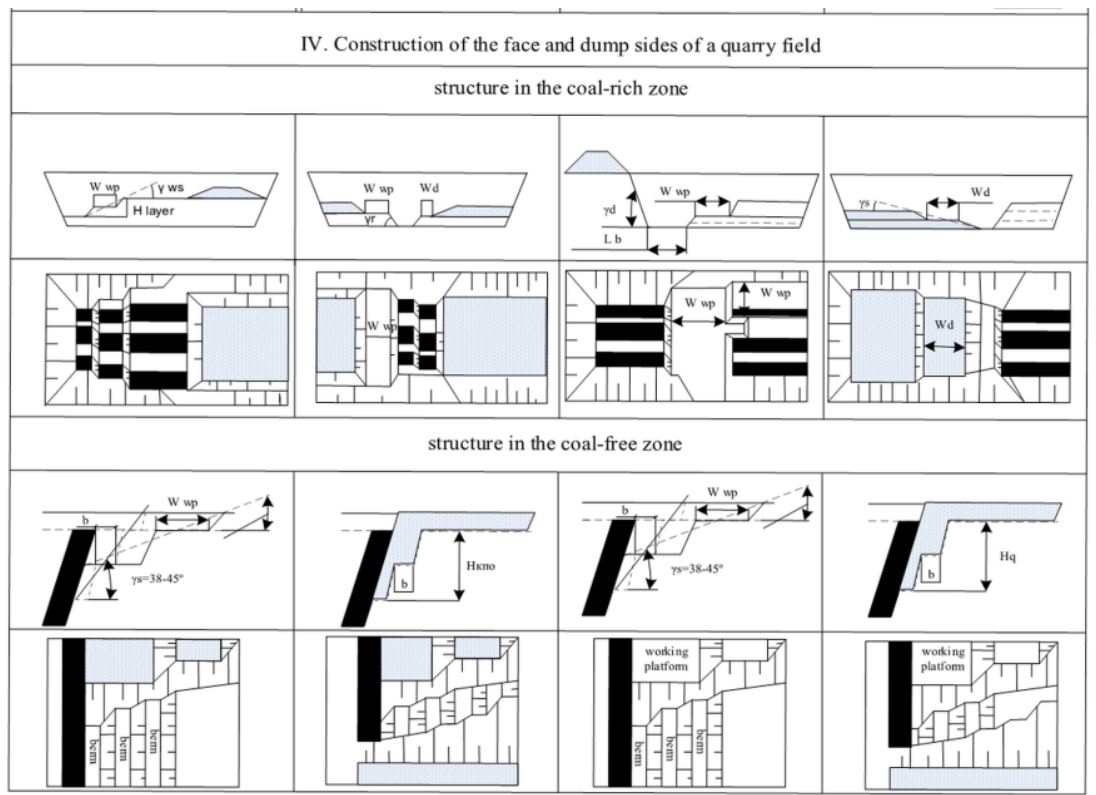

Fig. 4. Interpretation of the technological process of transformation of longitudinal deepening into transverse mining method for the operating surface mine (for shuttle and block-layer mining methods - Stage IV). 


\section{Results}

On the basis of comprehensive considering the spatial development of mining operations in the working area of the existing open pit (mined-out space), mineral reserves (coal content of the seam), annual production capacity, current stripping ratio and other factors, a mechanism was created for adapting technologies with internal dumping for the operating coal surface mine by means of the enlarged algorithm (Fig. 5) of the choice of the technology of internal dumping and the assessment of its influence on the technical and economic indicators after the implementation of the proposed solutions [9].

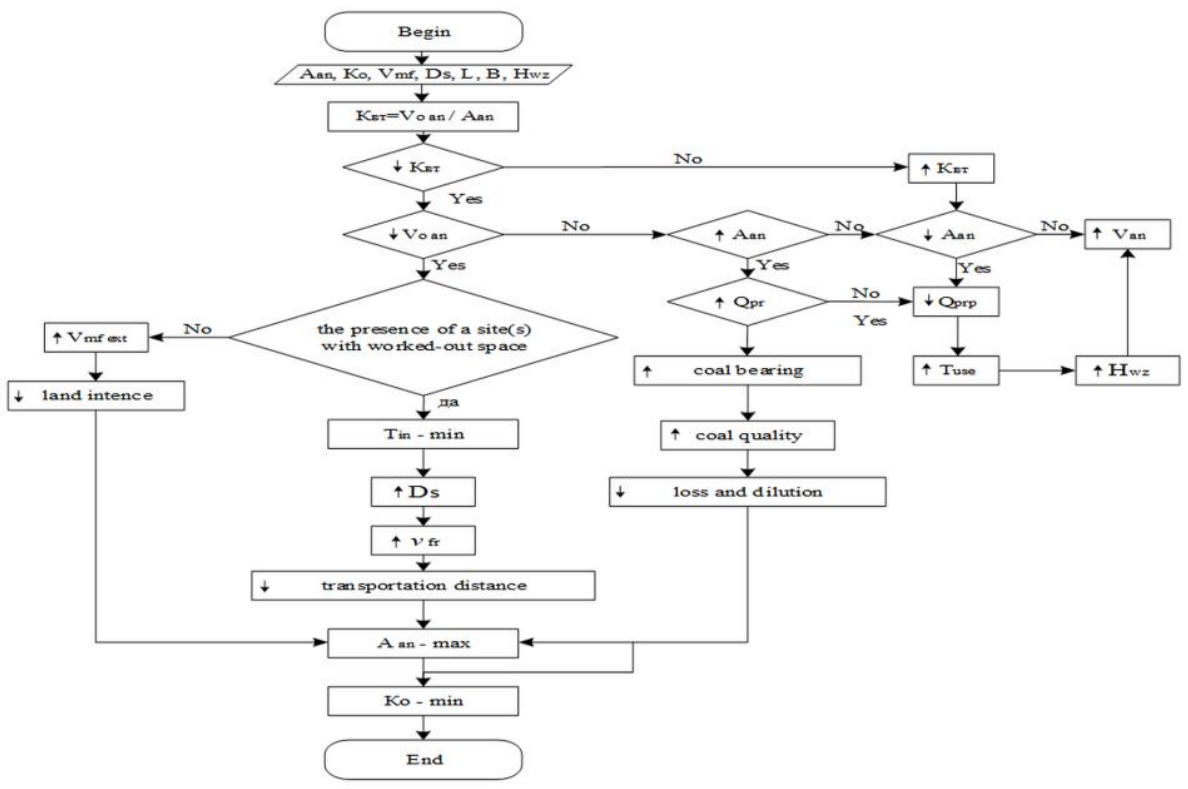

Fig. 5. An enlarged algorithm for evaluating the parameters and indicators of technological adaptation of internal dumping in the mode of operating surface mines.

In the Fig. 5, the following designations are adopted $K o$ - current stripping ratio $\mathrm{m} 3 / \mathrm{t}$; Tin - time of construction of the initial mine workings, years; Tuse - duration of operation of the enterprise, years; $Q p r$ - industrial reserves, million tons; $V f r$ - speed of advance of the work front, $\mathrm{m}$ / year; $D s$ - rate of the deepening, $\mathrm{m} /$ year; $H w z$ - height of the working zone, $\mathrm{m} ; L$ - length of the open pit at the top, $\mathrm{km} ; B$ - width of the open pit at the top, $\mathrm{m}$; $V a n$ - annual overburden volume, million $\mathrm{m}^{3} ; V m f$ ext - the volume of overburden placed on the external dump, million $\mathrm{m}^{3}$; Aan - annual productivity of the open pit, million tons (arrows ${ }^{\uparrow},{ }^{\downarrow}$ respectively, represent an increase or decrease in the indicator in the calculation algorithm).

As part of the implementation of the proposed solutions for the introduction of transverse mining method into mining practice, a software has been developed in "MS EXCEL" [10]. The software includes a multi-stage approach to the process of transforming a longitudinal mining method into a transverse one:

a) assessment of the state of mining operations at a surface mine (by key parameters and indicators of production activity);

b) the process of technological formation of one or another type of transverse mining method (location and parameters of the initial development for an internal dump, type of technology for conducting open pit mining); 
c) assessment of the impact of mining method with internal dumping on the operational activity of existing surface mines.

Implementation of resource-saving open pit mining into existing production by means of a calculation method, expressed through the above algorithm, makes it possible to additionally substantiate the parameters, indicators and areas of effective application of each form of the transverse mining methods.

\section{Conclusion}

The data obtained from the results of calculations made it possible to obtain the following conclusions and recommendations:

- increasing the efficiency of coal mining during the development of steep and inclined coal seams within the framework of traditional technologies is limited by the long-term non-use of the mined open pit space for the placement of overburden,

- the main method of managing the development of mining operations, in which the earlier use of the worked-out space for the placement of overburden rocks and the further continuous reproduction of this technogenic resource is achieved, is a phased change in the direction of the mining front,

- its local use in some open pit mines of the Kemerovo region confirms the high efficiency of involving this resource in the production process,

- the solution to the problem of resource saving in the development of steep and inclined coal seams is the transition to the proposed new technologies of open pit mining,

- the volume of overburden during the construction of the initial workings for the internal dump (taking into account the worked-out space) does not exceed $10-15 \%$ of the total volume of overburden of the quarry field;

- the duration of the transition from the deepening longitudinal to the transverse mining method during mining of inclined seams strata is 3-5 years, and for mining of steeply dipping seams $-5-8$ years, with the maximum share of the internal dump,

- to maintain operating of the enterprise with achieved technical and economic indicators during the construction of the initial workings, the annual capacity is maintained through the indicators of intensification of mining operations, and after the transition to internal dumping, it can increase by $15-20 \%$,

- it is possible to adapt the mode of internal dumping to the conditions of the existing open pit by the process of technological transformation with the maintenance of the achieved technical and economic indicators and a simultaneous decrease in the land capacity.

\section{References}

1. S. Zhironkin, A. Selyukov, M. Gasanov, Energies, 13(13), 3305 (2020)

2. V.V. Rzhevsky, Open mining operations. Part 2. Technology and complex mechanization ( Nedra, Moscow, 1985)

3. I.I. Tsepilov, A.I. Koryakin, V.F. Kolesnikov, S.I. Protasov, Prospective technologies for opencast mining of complex-structured coal deposits (KuzSTU, Kemerovo, 2000)

4. A. Selyukov, S. Zhironkin, M. Cehlár, Acta Montanistica Slovaca, 25(4), 542-562 (2020)

5. A.V. Selyukov, Assessment of the technological transition of the existing open-pit mine to internal dumping according to space-time criteria (KuzSTU, Kemerovo, 2009)

6. V.F. Kolesnikov, J. Janočko, Journal of Mining and Geotechnical Engineering, 2, 4274 (2020). doi: 10.26730/2618-7434-2020-2-42-74

7. B. Gerike, Yu. Drozdenko, D. Kopytin, Journal of Mining and Geotechnical Engineering 3, 58-78 (2020) doi: 10.26730/2618-7434-2020-3-58-78 
8. A. Selyukov, A. Gerasimov, K. Byrdin, E3S Web Conf., 105, 01047 (2019)

9. P.I. Tomakov, V.S. Kovalenko, Coal, 1, 36 (1992)

10. A.V. Selyukov, Simulation modeling in the Excel environment of the process of transition of the existing open-pit mines of Kuzbass to environmentally friendly transverse mining method (KuzSTU, Kemerovo) 